Chapter 12

\title{
Elaboration of Al-Mn Alloys by Aluminothermic Reduction of $\mathrm{Mn}_{2} \mathrm{O}_{3}$
}

\author{
A. Flores Valdés, J. Torres and R. Ochoa Palacios \\ Additional information is available at the end of the chapter \\ http://dx.doi.org/10.5772/50682
}

\section{Introduction}

Aluminium is the most abundant metallic element in earth, posing an excellent combination of chemical, mechanical and physical properties which made it suitable for many applications. Among its most important properties a low density, good corrosion resistance, and excellent thermal and electrical conductivities can be found. On the other hand, some aluminium alloys require higher mechanical properties, which are attainable by thermal or thermomechanical treatments. This is the case for extrusions or hot or cold rolled products [1].

Alloys of the Al-Mn-Mg series have been used as raw materials for the elaboration of beverage cans. In these alloys, the second phase particles such as $\beta-\mathrm{Al}_{6}(\mathrm{Fe}, \mathrm{Mn})$ or $\alpha-\mathrm{Al}_{12}(\mathrm{Fe}, \mathrm{Mn})_{3} \mathrm{Si}$ play an important role in the development of microstructure [2]. Precipitation characteristics in Al-Mn alloys are significantly affected by the presence of iron and silicon. It has also has been reported that both elements accelerate precipitation rate [3].

One of the best solutions to the problem of the accumulation of waste is recycling. In this way, considerably decreases the amount of debris without polluting the environment. Aluminium recycling reduces pollution by $90 \%$, and contributes to lower use of electricity, compared to processing primary raw materials [1].

Everyday increases the importance of recycling, especially when it comes to pollutants such as waste batteries. When running out and throwit away, they go to landfills, releasing highly toxic metal sand materials, adding to the water cycle through a in or gas produced by burning. The manufacture of batteries consume up to 50 times the energy they generate.

Recycling is extremely convenient for the production of goods, especially in countries that do not have the raw materials for the production of primary alloys. Some metals as aluminium can be recycled many times, as is the case of beverage cans. Chemical contamination of 
this kind of scrap often occurs, so the elaboration of alloys is based on smelting and refining special techniques. Nevertheless, recycling impacts directly in energy consumption savings and lower disposal costs.

\subsection{Recycling of aluminium cans}

Aluminium recycling is acomplex process, involving a variety of stages. The aluminium used comes primarily from two sources: waste either domestic consumptionor industrial (i.e., power lines, lithographic plates, beverage cans, other containers and packaging.); on the other hand, cut sand shavings produced during the manufacture of aluminium [3].

There are many types of aluminium alloys available in the market recovery, but basically can be groupedas follows [1]:

a. Rolled products (sheet of construction, printing plates, foil, vehicle body parts).

b. Extruded (profiles for windows, vehicle parts).

c. Molten aluminium alloys in metal molds, either by gravity or by injection(engine parts, handles of the doors).

d. Wiring for the manufacture of cables and other uses.

The most important alloys that can be elaborated using aluminium scrap are the Al-Si and Al-Si-Cu intended for the automotive industry. Nevertheless, other important alloys that can be elaborated from scrap are the well-known Al-Zn-Mg and complex Al-Si-Cu-Mg-Zn alloys.

Al-Mn alloys are not produced from scrap, rather they are obtained using primary smelting with commercial purity elements. Nevertheless, as it will be presented and discussed later, a good alternative is the usage of $\mathrm{Mn}_{2} \mathrm{O}_{3}$ powders obtained from discharged alkaline batteries, using aluminothermic reduction.

Aluminium does not changeits characteristics during there cycling, in addition beverage reservoirs can be madeentirely from recycled metal. Due to the high value of aluminium in the market, most cans are recycled in Mexico (98\%) and worldwide (66\%), allowing the city's image does not affector impair (hard to find canslying on street) and landfills do not increase their volume. In addition, recycling of metal packaging reduces contamination $[4,5]$.

Aluminium cansare very light when empty, in fact, in the last 15 years, the amount of aluminium used in the production of a can has been reduced by $35 \%$. Aluminium recycling provides energy savings and costs, when aluminium is used to manufacture the cans recovered instead of virgin materials. As large as $85 \%$ savings are obtained when recycling.

In conclusion, with its high level of recycling and being prepared with raw materials abundant in earth, aluminium cans are the quintes sentialeco-friendly-packaging materials. The malleability and resistance are some of the mainqualities and advantages of the cans, which allow a wide range of packaging products with different characteristics: from liquid and solid, to gaseous and aerosol products. Moreover, they can be used for packaging of some delicate products such as certain medications and some beauty products. Also flammable 
products that require optimal safety conditions such as paints, solvents, insecticides, fats, oils for industrial use,etc.

World wide consumption of cansis very high. By recycling this material generates a significant social conscience and is easy to convey the message to the population. Today the aluminium can recycling is an industry with large employment generation. It also has reduced energy consumption in the production of any material. This implies not only benefits the country level but also globally, because of environmental issues related to power generation [6].

Currently, the recycling of aluminiumis very common, and that all people want to recycle and benefit mostly by selling cheap, but not really worry about these contaminated waste.

\subsection{Recycling of alkaline batteries}

Several studies have been developed for the management of toxic substances that are dumped into the ecosystem, in order to reduce and/or eliminate pollution of the planet. A clear exampleis the subject of alkaline batteries, which have a high degree of toxicity components. The batteries are a source of energy producing electricity from chemical reactions, but once discharged, are especially dangerous waste. When a battery loses its protective covering, being exposed to the weather, it releases toxic metals and materials known to beharmful effects to the ecosystemand health of human beings. These metals and toxic material shave harmful effects on human health ranging from serious injuryin the central nervous system lesions in the liver, kidney affections, gastrointestinal disorders, carcinomas or getting even death [7]. Alkaline batteries have duration of three or more times than other primary batteries.

\begin{tabular}{clc}
\hline Kind of battery & \multicolumn{1}{c}{ Components } & Uses \\
\hline Alkaine & ${ }^{*}$ Zinc: $15 \%$ (anode) & Electric and electronic devices, \\
& ${ }^{*}$ Manganese dioxide: $35 \%$ (cathode) & known as common batteries \\
& *Carbon: $\%$ \\
& *Potassium hidroxide: $8 \%$ & \\
& *Plastic and sheet: $40 \%$
\end{tabular}

Table 1. Components and applications of alkaline batteries.

Alkaline batteries using an electrochemical system in which the zinc and manganese dioxideare the anode and cathode respectively, the overall reaction in analkaline battery is represented by:

$$
\mathrm{Zn}+2 \mathrm{MnO}_{2} \rightarrow \mathrm{Mn}_{2} \mathrm{O}_{3}+\mathrm{ZnO}
$$


So that the products at the anode and cathode of analkaline battery discharged are $\mathrm{ZnO}$ and $\mathrm{Mn}_{2} \mathrm{O}_{3}$, respectively.

Some dangers identified during use of the batteries are accidental break age of the shield, with the corresponding stroke of the components. When the batteries are subjected to extreme environmental conditions than those experienced on the interior of a computer, the shield is exposed to corrosion processes ending and releasing destroying cell components. Multiplying the number of batteries used by each in habitant, the number of people highlights the way in how they are polluting the planet [8,9]. Alkaline batteries are considered hazardous waste dischargedand forbidden to be deposited a long with the regular trash in landfills.

Different technologies have been developed for the handling of this kind of waste, in order to establish the most appropriate provisions of the discharged electric batteries [2]. There are many alternatives that can be applied, among which are: collection, stabilization, confinement, glazing, ceramization and recycling of components.

The use of recycled materials such as aluminium cans and alkaline cathodes as the raw material for the manufacture of aluminium-manganese alloys by metallothermic reduction is highly suitable. Therefore, one of the objectives of this study was to analyze the relationship between the microstructure and mechanical properties (hardness, tensile strength, and elongation) of Al-Mn alloys produced by aluminothermic reduction both in the as-cast condition and after homogenization annealing.

\subsection{Metallothermic reduction of oxides}

Metallothermic process relates to the production of metals andalloys by reducing their oxides or halides with metals. Generally, these reactions can be expressed by the equation $[10,11]$ :

$$
A X+B \rightarrow A+B X
$$

Where Xis oxygen, chlorine or fluorine, and Aand B represent the two metals.

The main characteristic of this process is that the metal being reducedis converted into a solid or liquid, which dissolves in the molten metal. Metallothermic processes are used when the reduction with carbon, hydrogenor by electrolys is of a solution is not possible. Among the metals used as reducing agents are: $\mathrm{Al}$, CaandMg.

Figure 1 shows a schematic representation of the aluminothermic reduction, in which the particles of manganese oxide $\left(\mathrm{Mn}_{2} \mathrm{O}_{3}\right)$ is reduced by molten aluminiumat the boundary layer. 


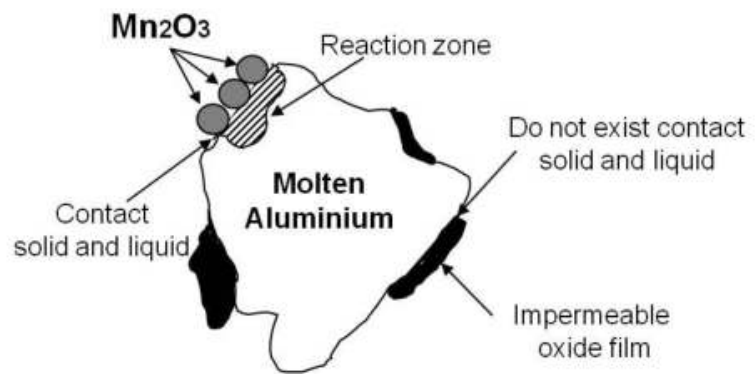

Figure 1. Scheme of the aluminothermic reduction of $\mathrm{Mn}_{2} \mathrm{O}_{3}[10,11]$.

\subsubsection{Influenc surface tension in the metallothermic process}

The nature of the interfaces of the species that are in contact is critical to achieving the wettability required for a reaction to occur between them, either dissolution or chemical reaction. For the alumin other mic reaction it is required very good contact between liquid and solid particles of the oxides to reduce. Therefore, without a good wettability, chemical reaction rates of mass transport and are greatly reduced. In the extreme case where the wettability between the solid oxideand the molten phase does not exist, the reaction will not occur [12].

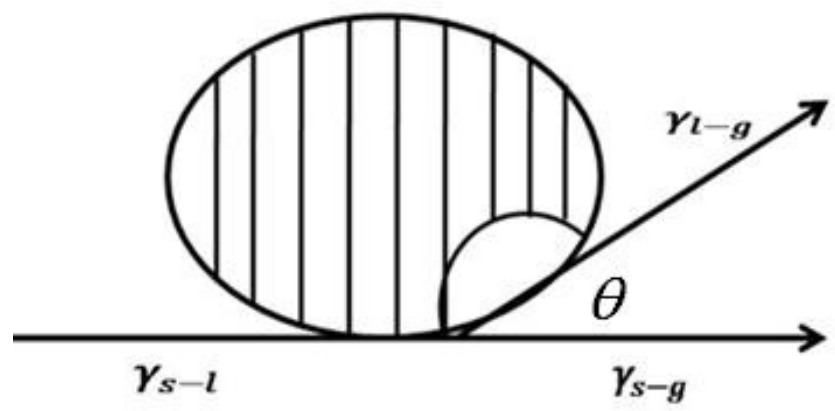

Figure 2. Scheme of the method of measurement of the contact angle between a solid and a molten phase [12].

Many solutes in liquid metals can act as surface active agents (such as soap in the water) which have a lower surface tension. Generally, measuring the contact angle, $\theta$, is the most commonly applied to determine the wettability which occurs between the solid and liquid. Such measurements are performed in the liquid phase as shown in Figure 2. If the liquid phase takes hold on the solid surface with amorphology very close to that of a sphere, the contact angle will be large and will reach the limit of $90^{\circ}$, so that there will be no wettability. Otherwise, if the liquid phase tends to wet the solid phase, the value of angle $\theta$ is small and reaches the limit $0^{\circ}$. 
The two limits represent the conditions for a complete and in complete wettability, respectively. Assuming that a liquid, L, lies on the solid surface, S, in contact with an inert gas G, in equilibrium, the liquid dropand the solid surface will be a tan angle $\theta$ as shown in the following equation:

$$
\vartheta_{S L}=\vartheta_{S G}+\vartheta_{L G} \cos \cos \omega
$$

Where $\gamma_{\mathrm{SL}}, \gamma_{\mathrm{SG}}$ and $\gamma_{\mathrm{LG}}$ are the surface tension between the solid-liquid, solid-gas and liquidgas, respectively.Therefore, the theoretical contact angle can be represented by the following equation:

$$
\operatorname{Cos} \operatorname{Cos} \omega=\left[\frac{\vartheta_{S G}-\vartheta_{S L}}{\vartheta_{L G}}\right]
$$

Using this equation,the contact angle between the solid toliquid aluminium can be compared. Equation (4) maybe written also as follows:

$$
\operatorname{Cos} \operatorname{Cos} \omega=\left[\frac{\vartheta_{S G}-f\left(\vartheta_{S L}\right)}{\vartheta_{L G}}\right]
$$

Meaning that the surface tension, $\gamma_{\mathrm{SL}}$, varies proportionally with the surface tension $\gamma_{\mathrm{LG}}$. Therefore, by increasing $\gamma_{\mathrm{LG}}$, the contact angle, $\theta$, is also increased. A lower contact angle means better wettability of the solid surface. Surface tensions of the liquids are high and the typical values of most representative metals are listed in Table 2.

\begin{tabular}{ccc}
\hline Metal & $\mathbf{V}_{\mathrm{LG}}$ & $\mathrm{V}_{\mathrm{SL}}$ \\
\cline { 2 - 3 } & $(\mathbf{d y n} / \mathbf{c m})$ & $(\mathbf{d y n} / \mathbf{c m})$ \\
\hline $\mathrm{Mg}$ & 559 & 56 \\
\hline $\mathrm{Al}$ & 914 & 91 \\
\hline $\mathrm{Si}$ & 865 & 86 \\
\hline $\mathrm{Ca}$ & 361 & 36 \\
\hline $\mathrm{Sr}$ & 303 & 30 \\
\hline $\mathrm{Bi}$ & 378 & 38
\end{tabular}

Table 2. Surface tension for metals in the alumino thermic process [10].

The surface tension values for magnesium are minor compared to that of pure aluminium. Therefore, the magnesium improves the wettability between the solid and the liquid metal. 


\subsubsection{Effect of magnesium in the metallothermic reduction}

In the metallothermic reduction process with aluminium, magnesium has attracted much attention due to their surfactant nature, since the value of the surface tension of this element is less compared with that of pure aluminium $\left(\gamma_{\mathrm{Mg}}=559 \mathrm{dyn} / \mathrm{cm} ., \gamma_{\mathrm{Al}}=914 \mathrm{dyn} / \mathrm{cm}\right)[10,13]$. Therefore, the addition of magnesium reduces the surface tension of molten aluminium bath which leads to improve the wettability between the solid reactant and the liquid metal, thus increasing the kinetics of the reactions taking place at the solid-liquid interface.

From the thermo dynamic point of view, magnesium dissolved in theliquid has an affinity foroxygen, as seen by the Gibbs free energy values of the following reactions:

$$
\begin{gathered}
2 \mathrm{Mg}+\mathrm{O}_{2}=2 \mathrm{MgO} \beta G_{1073 \mathrm{~K}}^{\circ}=-231^{\mathrm{kcal}} / \mathrm{mol} \\
4 / 3 \mathrm{Al}+\mathrm{O}_{2}=2 / 3 \mathrm{Al}_{2} \mathrm{O}_{3} \beta G^{\circ}{ }_{1073 \mathrm{~K}}=-319^{\mathrm{kcal}} / \mathrm{mol}
\end{gathered}
$$

The thermo dynamic stability of magnesium oxide ( $\mathrm{MgO})$ suggests that the magnesium dissolved in the liquid aluminium in creases the reactivity of the process [ $\left.{ }^{10}\right]$, and therefore the concentration of manganesein the molten metal could in crease.

For the case of the metallothermic reduction of manganese trioxide, reactions taking place are the following:

$$
\begin{gathered}
2 \mathrm{Al}+\mathrm{Mn}_{2} \mathrm{O}_{3}=2 \mathrm{Mn}+\mathrm{Al}_{2} \mathrm{O}_{3} \beta G_{1048 \mathrm{~K}}^{\circ}=-156.940^{\mathrm{kcal}} / \mathrm{mol} \\
3 \mathrm{Mg}+\mathrm{Mn}_{2} \mathrm{O}_{3}=2 \mathrm{Mn}+3 \mathrm{MgO} \beta G_{1048 \mathrm{~K}}^{\circ}=-185.331^{\mathrm{kcal}} / \mathrm{mol} \\
6 \mathrm{Al}+3 \mathrm{Mg}+4 \mathrm{Mn}_{2} \mathrm{O}_{3}=8 \mathrm{Mn}+3 \mathrm{MgAl}_{2} \mathrm{O}_{4} \beta \mathrm{G}_{1048 \mathrm{~K}}^{\circ}=-656.151^{\mathrm{kcal}} / \mathrm{mol}
\end{gathered}
$$

According to the above, it is possible to obtain alloys Al-Mn from recycled cathode alkaline discharge dusing the metallothermic reduction reaction with the molten metal obtained from the smelting of aluminium cans.

\subsection{Al-Mn alloys}

Aluminium alloys of the series 3000 (Al-Mn) are perhaps the most important of aluminium strain hardened alloys. Generally, they contain from $0.25-1.50 \mathrm{wt}$ \% $\mathrm{Mn}, 0.05-0.2 \mathrm{wt} \% \mathrm{Cu}$, 0.1 wt. \% $\mathrm{Zn}$ and small percentages of elements such as $\mathrm{Mg}, \mathrm{Cr}, \mathrm{Fe}, \mathrm{Si}$, and Ni.Due to its excellent mechanical properties, they have several applications, such as food processing, textiles and automotive products, cookware, pressure vessels, construction elements, panels for refrigerators and heat exchangers. 
According to the equilibrium diagram Al-Mn of Figure 3 [14], the aluminium forms aeutectic with the inter metallic $\mathrm{Al}_{6} \mathrm{Mn}$ at a temperature of $658^{\circ} \mathrm{C}$ and a composition of $1 \% \mathrm{Mn}$. The presence of $\mathrm{Fe}, \mathrm{Mg}$ and Siimpurities is inevitable, changing on set temperatures of reactions and solidification temperatures. First, the phase $\mathrm{Al}_{6} \mathrm{Mnis}$ replaced by $\mathrm{Al}_{15}(\mathrm{Mn}, \mathrm{Fe})_{3} \mathrm{Si}_{2}$ appearing also particles of the $\mathrm{Mg}_{2} \mathrm{Si}$ phase. The characteristic temperatures of solidificationare reduced some what by the presence of $\mathrm{Si}$ and $\mathrm{Fe}$, starting with the formation of primary aluminium grain sat $652^{\circ} \mathrm{C}$. The phase $\mathrm{Al}_{6}(\mathrm{Fe}, \mathrm{Mn})$ is formed around $644^{\circ} \mathrm{C}$ by an eutectic reaction, the temperature is at least $10^{\circ} \mathrm{C}$ lower than that of analloy of magnesium free (3003).

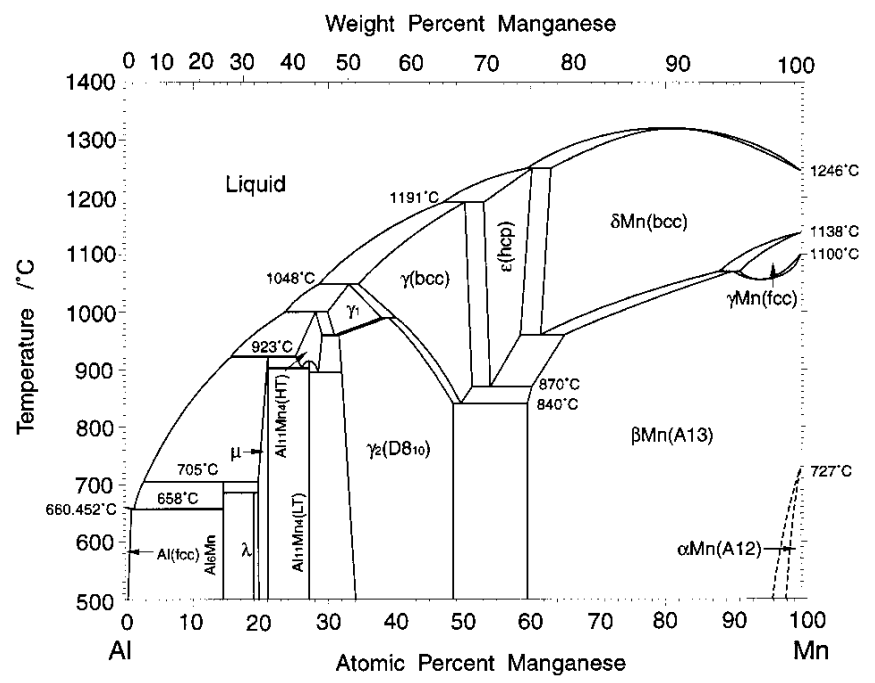

Figure 3. The Al-Mn phase diagram [14].

The inter metallic $\mathrm{Al}_{6}(\mathrm{Fe}, \mathrm{Mn})$ reacts with the liquid phase through a peritectic reaction at $630^{\circ} \mathrm{C}$ to form $\mathrm{Al}_{15}(\mathrm{Mn}, \mathrm{Fe})_{3} \mathrm{Si}_{2}$. An observation made by Bäckerud [10] is that, contrary to the usual trend, the peritectic reaction is complete at high cooling rates and partially at slower cooling rates. This explains why the particle size of $\beta-\mathrm{Al}_{6}(\mathrm{Fe}, \mathrm{Mn})$ thicken at low cooling rates. Solidification ends around $580^{\circ} \mathrm{C}$ with the formation of $\mathrm{Mg}_{2} \mathrm{Si}$ by an eutectic reaction. The particles of $\beta-\mathrm{Al}_{6}(\mathrm{Fe}, \mathrm{Mn})$ remaining in the melt due to incomplete peritectic reaction, must be dissolved during annealing, resulting in the more stable phase $\mathrm{Al}_{15}(\mathrm{Fe}, \mathrm{Mn})_{3} \mathrm{Si}_{2}[2]$.

\begin{tabular}{ccccccc}
\hline Elemet & Si & Fe & Cu & Mn & Mg & Zn \\
\hline wt. \% & 0.3 & 0.7 & 0.25 & $1.0-1.5$ & $0.8-1.3$ & 0.25
\end{tabular}

Table 3. Typical composition of a 3004 alloy, in wt. ${ }^{[8]}$. 
These alloys have only a $20 \%$ higher hardness than pure aluminium. The chemical composition of alloy 3004 is presented in Table 3.

Min may be added effectively at only 1.5 wt. \% (see Figure 3). Therefore, there are very fealloys of this eries. However, the 3003, 3004 and 3005 alloys are used for making tools that need medium hardness and good formability, for applications such as beverage cans, kitchen utensils, heat exchangers, furniture, signs and architectural applications.

The 3004 alloy also contains magnesium, improving the mechanical properties while enhancing resistance to corrosion. Due to the high content of $\mathrm{Mg}$ in the molten phase coming from cans, it can be used to promote metallothermic reduction of manganese oxides, producing alloys of the 3000 series type, where the initial content of $\mathrm{Mg}$ could decrease below 0.3 in wt. \%.

1. la

2. el

3. $\operatorname{los}$

4. las

5. 10

\section{Experimental procedure}

This section describes both the experimental design and melting practices carried out for the production of Al-Mn alloys by aluminothermic reduction of $\mathrm{Mn}_{2} \mathrm{O}_{3}$.

\subsection{Materials and Equipment}

To obtain the Al-Mn alloy it is required:

- Alkaline Battery Cathodes $\left(\mathrm{Mn}_{2} \mathrm{O}_{3}\right.$ powders).

- Aluminium cans.

Medium frequency induction furnace.

Metal Molds

For characterization of the samples:

- Chemical analysis (Inductively Coupled Argon Plasma Spectrometry and Atomic Absorption)

- Scanning Electron Microscopy(EBSD).

- Quantitative Optical Microscopy(EDS).

- X-Ray diffraction. 
Variables analyzed were target concentration of Mn in the alloy (1-1.5 wt. \%), which caused that treatment time varied from 120 of up to 240 minutes, and temperature (1023, 1050 and $1073 \mathrm{~K})$. The powders used were of the constant size of 240 mesh, while agitation speed was maintained constant at $200 \mathrm{rpm}$.

It is worth mentioning that $\mathrm{Mn}_{2} \mathrm{O}_{3}$ powders were obtained in its purified form and of constant size, from discharged alkaline batteries, through a procedure reported elsewhere [8].

\subsection{Methodology}

\subsubsection{Melting Practice}

For Al-Mn alloys obtention using aluminothermic reduction of $\mathrm{Mn}_{2} \mathrm{O}_{3}$, the melting of aluminium cans was carried out using a medium frequency induction furnace. The cans were loaded to the furnace in charges of $10 \mathrm{~kg}$. Once the temperature reached the value of interest, i.e. $1023 \mathrm{~K}$, it was maintained constant up to completion of treatment time. During each experiment, samples from the melt were taken every 10 minutes. At the end of each experiment, fluxing and degassing was performed, in order to obtain solid enough samples for mechanical properties measurements. Table 4 shows the chemical composition of the alloy obtained from the fusion of aluminium cans.

\begin{tabular}{ccccccc}
\hline Elemet & Si & Fe & Cu & Mn & Mg & Zn \\
\hline wt. \% & 0.338 & 0.603 & 0.169 & 0.832 & 1.02 & 0.698
\end{tabular}

Table 4. Chemical composition of the starting alloys from recycled aluminium cans.

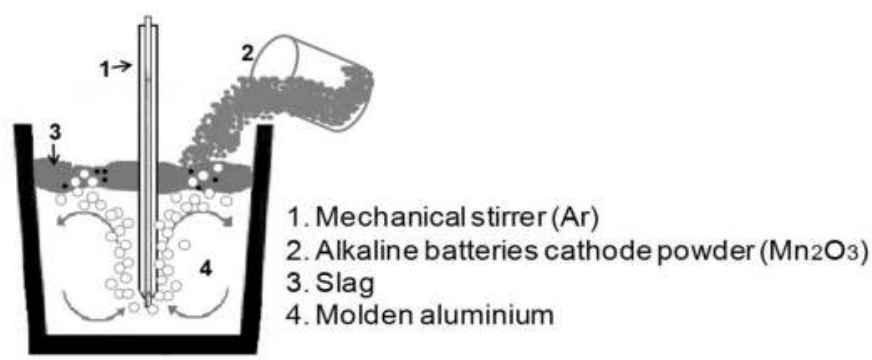

Figure 4. Scheme of the form of powders addition using a mechanical stirrer.

As reactive powders it were used those obtained from discharged alkaline cathodes $\left(\mathrm{Mn}_{2} \mathrm{O}_{3}\right)$, previously separated from other components of the batteries and properly milled up to obtaining a -240 mesh size particles. The addition of $\mathrm{Mg}$ was done in the form of scrap, in order to reach for an initial concentration of 1.75 wt. \% [10]. After finishing Mg adjustment, mechanical stirrer is placed, which is cylindrical in shape and made of graphite, using 
a constant stirring rate of $200 \mathrm{rpm}$. A scheme of the methodology of powders addition is shown in Figure $4 . \mathrm{Mn}_{2} \mathrm{O}_{3}$ is added depending on the target concentration of $\mathrm{Mn}$ needed. This additionis done inperiods of time of 20 minutes each. Treatment time varied from 120 minutes for the case of a concentration of $1 \mathrm{wt}$ \% Mn, to 150 and 240 minutes for the higher Mn concentrations.

\section{Results and discussion}

This section presents and discusses the results obtained from the manufacture of Al-Mn alloys from recyclable materials (aluminium cans and alkaline battery cathodes discharged) by the aluminothermic reduction process.

\subsection{Al-1 wt.\% Mn alloys}

Chemical analysis results show that the Mn contentin the alloy in creases with in creasing treatment time, suggesting that the aluminothermic reduction of $\mathrm{Mn}_{2} \mathrm{O}_{3}$ takes place with in the molten metal. Figure 5 shows the variation of the concentration of both $\mathrm{Mg}$ and $\mathrm{Mn}$ as a function of $\mathrm{Mn}_{2} \mathrm{O}_{3}$ powders addition time. It is observed that the $\mathrm{Mg}$ content decreases from $1.75 \%$ to 1.25 wt. \%,so the metallothermic reduction reactionis carried out by $\mathrm{Al}$ and $\mathrm{Mg}$ from the molten alloy, while Mn increased from 0.83 to1.08 wt. \%.

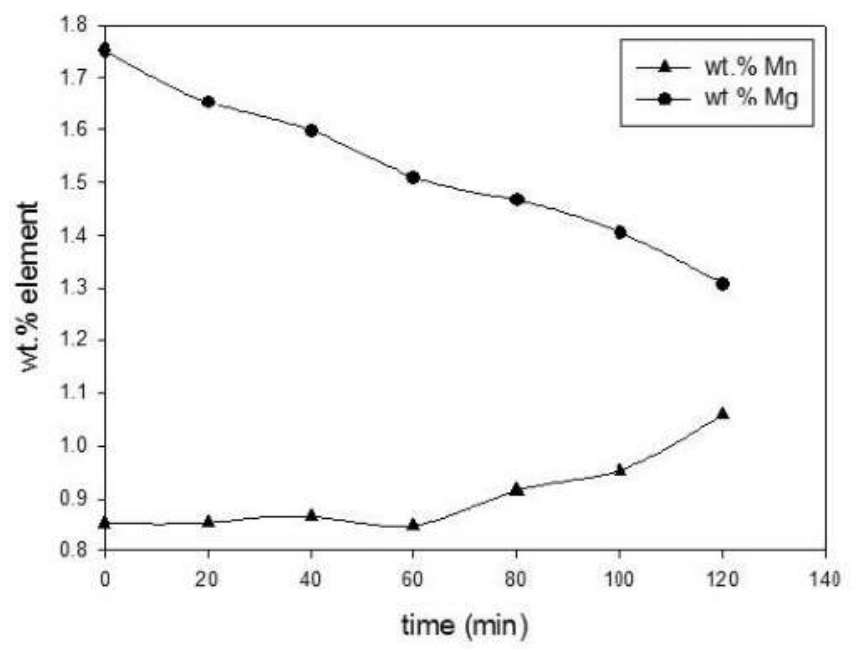

Figure 5. Variation of the concentrations of $\mathrm{Mn}$ and $\mathrm{Mg}$, with respect to treatment time, during the metallothermic reduction of $\mathrm{Mn}_{2} \mathrm{O}_{3}$, for a target $\mathrm{Mn}$ concentration of $1 \mathrm{wt}$. \% at constant temperature.

According to the equilibrium diagram Al-Mn-Fe, it is observed that manganese concentrations achieved in these experiments form on solidification the $\beta-\mathrm{Al}_{6}(\mathrm{Fe}, \mathrm{Mn})$ phase. When 
the concentration of $\mathrm{Mn}$ increases in the alloys, the percentage in area of the $\mathrm{Mn}$ rich phase increases. Furthermore, there is a stepped behavior, which can be attributed to the formation of reaction products around the particles acting as a barrier in the metallothermic reduction of $\mathrm{Mn}_{2} \mathrm{O}_{3}$. According to reactions (8) and (10), the stable compounds that are formed are $\mathrm{Al}_{2} \mathrm{O}_{3}$ and $\mathrm{MgAl}_{2} \mathrm{O}_{4}$, which surrounds the particles of manganese oxide, causing the metallothermic reduction becomes relatively slow. As this stage is the slowest one during the alumino thermic reduction process, it can be established that it control the diffusion of species such as $\mathrm{Al}, \mathrm{Mg}$ and $\mathrm{Mn}$ through the layers formed. It probably requires more processing time to increase the concentration of $\mathrm{Mn}$ in the liquidor an increase in the amount of $\mathrm{Mn}_{2} \mathrm{O}_{3}$ for the metallothermic reaction.

Figure 6 shows a typical x-ray diffraction pattern of a slag sampled at the end of the experiment described above, where it is evident the formation of such mineralogical species as $\mathrm{Mn}_{2} \mathrm{O}_{3}, \mathrm{Al}_{2} \mathrm{O}_{3}$ and $\mathrm{MgAl}_{2} \mathrm{O}_{4}$. From this pattern, the most important features are the appearing of spinel and $\mathrm{Al}_{2} \mathrm{O}_{3}$, corroborating that these are the reaction products according to reactions (8) and (10) given above.

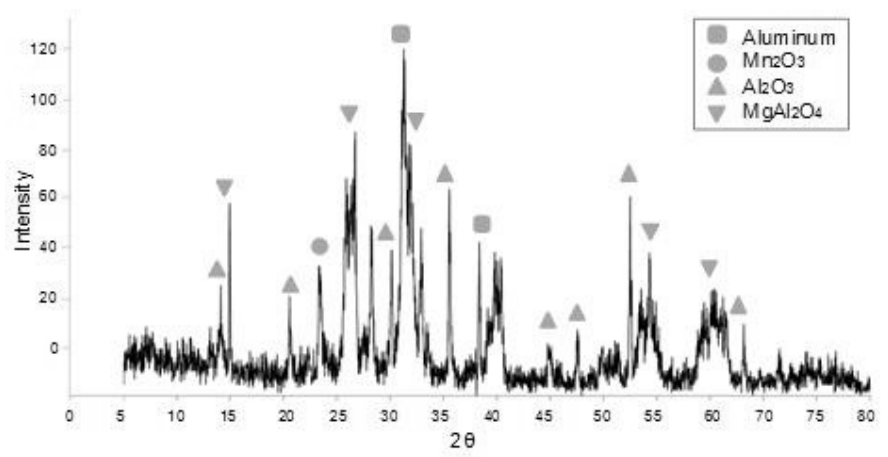

Figure 6. X-ray diffraction pattern of a slag sampled at the end of the experiment where an alloy Al-1Mn was obtained.

\subsection{Al-1.25 wt. \% Mn alloys}

Figure 7 shows the variation of the concentration of both $\mathrm{Mg}$ and $\mathrm{Mn}$ as a function of $\mathrm{Mn}_{2} \mathrm{O}_{3}$ powders addition time, when the target concentration of Mn was $1.25 \mathrm{wt}$. \%. It is observed that the $\mathrm{Mg}$ content decreased from 1.78 wt. \% to 1.35 wt. \%, while Mn concentration increased from 0.825 to $1.27 \mathrm{wt}$. \%, as of the aluminothermic reduction reaction. Treatment time was 150 minutes, showing a slightly linear behavior of manganese concentration increase until 110 minutes, noting a sharp increase there after. This confirmed that the aluminothermic reduction of $\mathrm{Mn}_{2} \mathrm{O}_{3}$ requires more processing time to increase the concentration of $\mathrm{Mn}$ in the molten metal. 


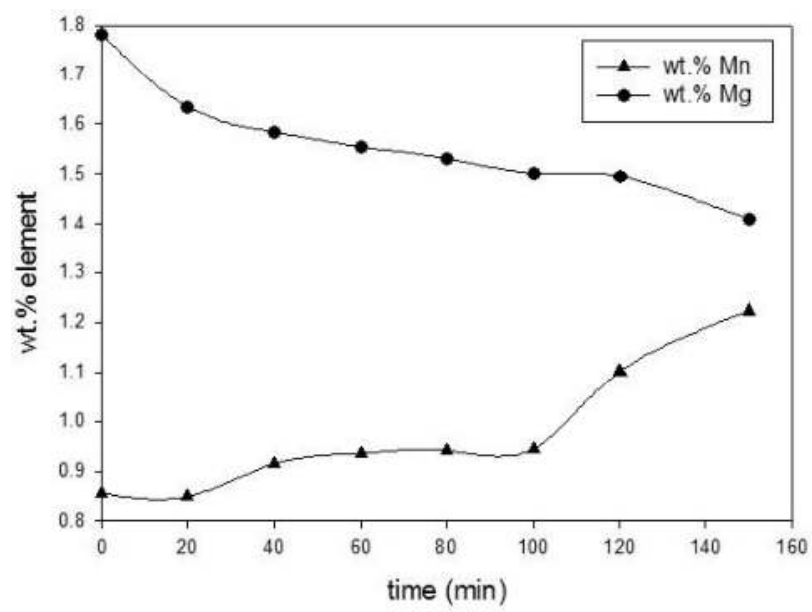

Figure 7. Variation of the concentrations of $\mathrm{Mn}$ and $\mathrm{Mg}$, with respect to treatment time, during the metallothermic reduction of $\mathrm{Mn}_{2} \mathrm{O}_{3}$, for a target $\mathrm{Mn}$ concentration of 1.25 wt. \% at constant temperature.

Also the reaction product obtained were $\mathrm{Al}_{2} \mathrm{O}_{3}$ and $\mathrm{MgAl}_{2} \mathrm{O}_{4}$, which are formed around the particles of manganese trioxide, causing that the aluminothermic reduction becomes relatively slow, controlling the diffusion ofthe chemical species such as $\mathrm{Al}, \mathrm{Mg}$ and $\mathrm{Mn}$ through the formed layers.

\subsection{Al-1.50 wt. \%Mn alloys}

Figure 8 shows the variation of the concentration of both $\mathrm{Mg}$ and $\mathrm{Mn}$ as a function of treatment time, when the target Mn concentration was 1.5 wt. \%. From this graph, it is observed that the $\mathrm{Mg}$ content decreased from 1.76 wt. \% to 1.20 wt. \%, while Mn concentration increased from 0.83 to $1.50 \mathrm{wt}$. \% after 240 minutes. It should be mentioned that according to the literature, it can only be added up to $1.5 \mathrm{wt}$. \% $\mathrm{Mn}$, no matterif the $\mathrm{Mg}$ concentration is increased to levels around 2 wt. \%. In this case, it is established that the maximum concentration of $\mathrm{Mn}$ is $1.5 \%$, even when treatment time increased.

Also the reaction products obtained were the stable compounds $\mathrm{Al}_{2} \mathrm{O}_{3}$ and $\mathrm{MgAl}_{2} \mathrm{O}_{4}$, which are formed around the particles of manganese oxide, having a similar behavior to that presented in the paragraphs previously discussed.

Figure 9 shows the trend in the variation of Mn concentration as of the aluminothermic reduction of $\mathrm{Mn}_{2} \mathrm{O}_{3}$, where the effect of temperature on reaction rate is evident. As it can be seen from this graph, the higher the temperature, the higher the final Mn concentration reached in molten aluminium. This is attributed to the fact that the reaction depends strongly on diffusion of chemical species such as $\mathrm{Al}, \mathrm{Mg}$ and $\mathrm{Mn}$ to the boundary layer, where chemical reactions are taking place. 


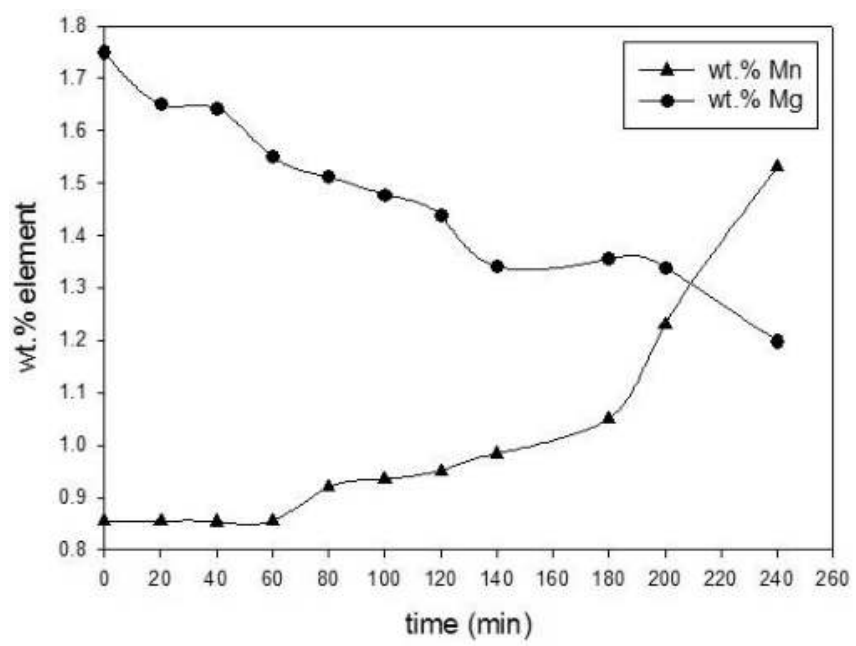

Figure 8. Variation of the concentrations of $\mathrm{Mn}$ and $\mathrm{Mg}$, with respect to treatment time, during the metallothermic reduction of $\mathrm{Mn}_{2} \mathrm{O}_{3}$, for a target $\mathrm{Mn}$ concentration of $1.50 \mathrm{wt}$. \% at constant temperature.

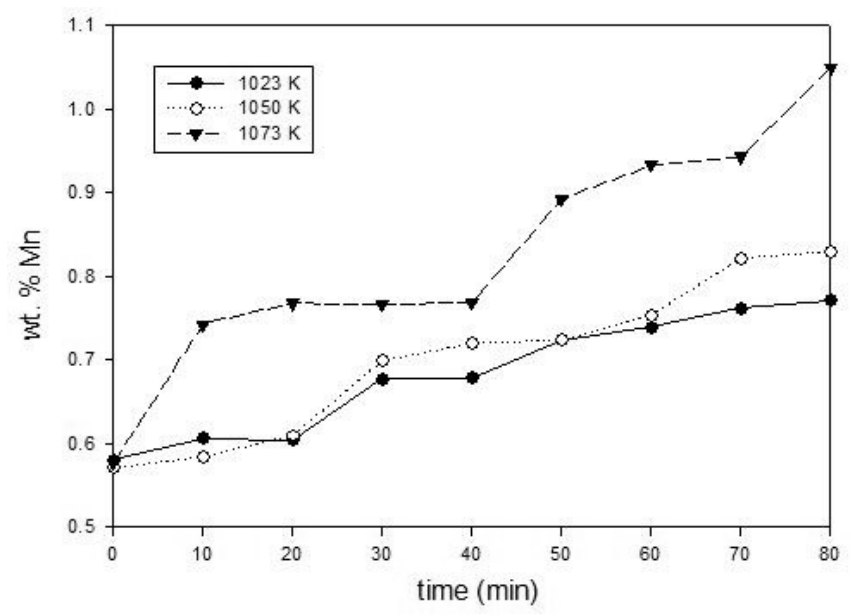

Figure 9. Trend in the variation of Mn concentration as a function of treatment time, showing the effect of temperature.

\subsection{Reaction kinetics of the aluminothermic reduction process of $\mathrm{Mn}_{2} \mathrm{O}_{3}$}

The results of $\mathrm{Mn}$ concentration increase in molten aluminium as of a function of treatment time for the aluminothermic reduction of $\mathrm{Mn}_{2} \mathrm{O}_{3}$ in liquid aluminium shown in Figure 9 could be used to determine some values of kinetic parameters of interest. After using the 
differential method, the reaction orderfor the aluminothermic reduction of $\mathrm{Mn}_{2} \mathrm{O}_{3}$ is zero, being represented by the next equation:

$$
\frac{d[x]}{d t}=-k(\text { Ordenzero })
$$

From the slopes of the linear relationship between $\mathrm{Ln}\left(\mathrm{dc}_{\mathrm{Mn}} / \mathrm{dt}\right)$ versus $\mathrm{Ln}\left(\mathrm{C}_{\mathrm{Mn}}\right)$ shown in Figure 10, the values of the order of reaction were determined.

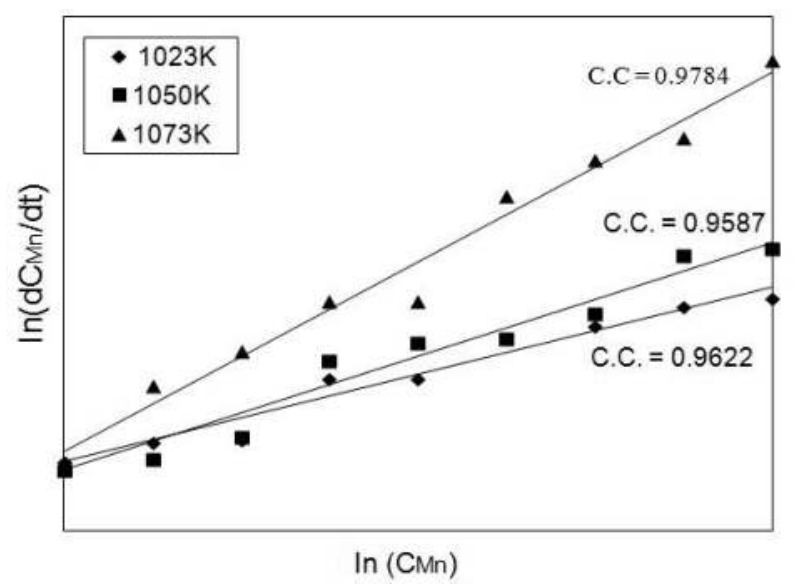

Figure 10. Linear plotof Mncontractionversusreaction time, for determining theorder ofreaction.

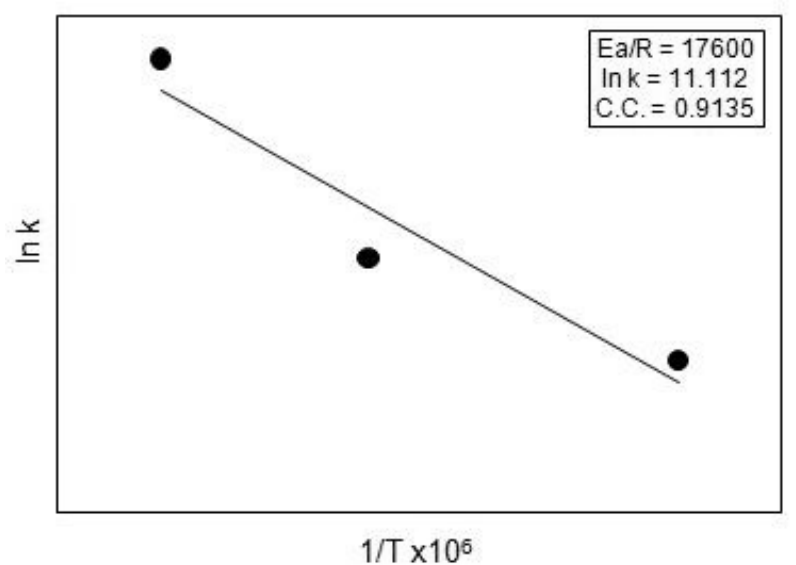

Figure 11. Linear plot of In k vs $1 / \mathrm{T}$, for determining the activation energy in the aluminothermic reduction of $\mathrm{Mn}_{2} \mathrm{O}_{3}$. 
Average value of reaction order was 1.0. Furthermore,from this graph, the values of the rate constant(k) could be determined. The rate constant values were also obtained using the differential method.

From the values of reaction rate $(k)$ for each temperature, the activation energy(Ea) using the Arrhenius formula could be determined. Figure 11 shows the linear relationship of $\ln k$ versus $\ln 1 / \mathrm{T}$, resulting in a value of $\mathrm{Ea}=146 \mathrm{~kJ} / \mathrm{mol}$.

According to the value of activation energy for the aluminothermic reduction of $\mathrm{Mn}_{2} \mathrm{O}_{3}$, it can be established that the reactionis governed by diffusive processes ${ }^{[1]}$.

\subsection{Micro structures obtained}

The incorporation of $\mathrm{Mn}$ from the chemically reduced metaloxide to the molten metal was corroborated by optical microscope. Figure 12 shows photo micrographs of alloys with the final manganese concentrations indicated.

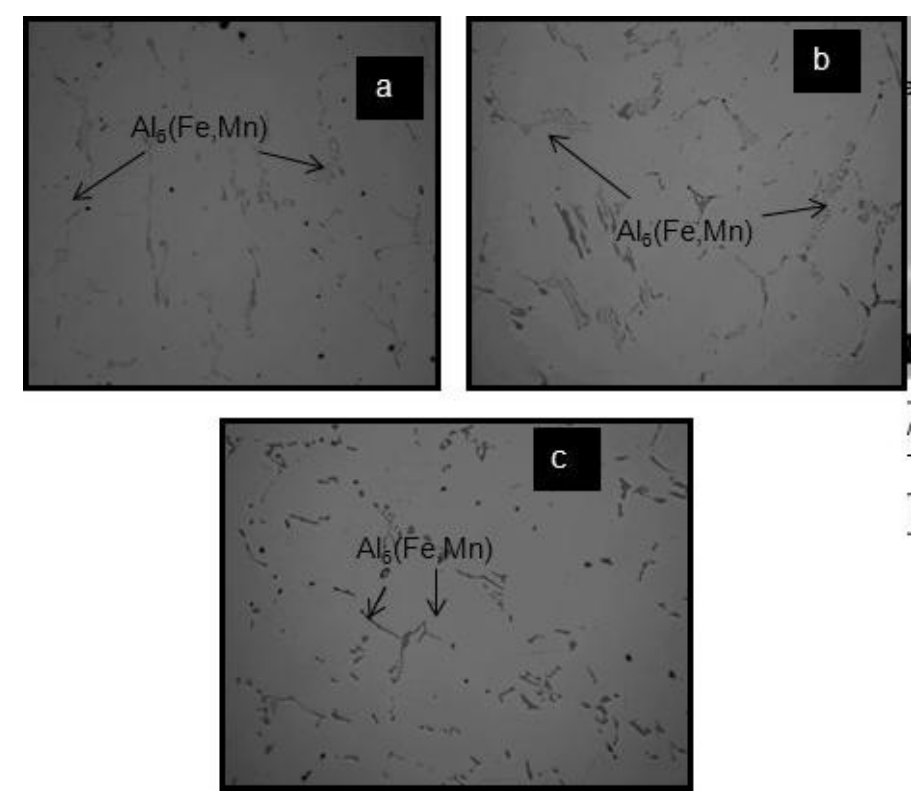

Figure 12. Photo micrographs showing the microstructure of: a) alloy with 1 wt. \%Mn; b) alloy with 1.25 wt. \%Mn; c) alloy with 1.5 wt. \%Mn.

In these cases, the particles shown correspond to the formula $\beta-\mathrm{Al}_{6}(\mathrm{Fe}, \mathrm{Mn})$, that were determined by microprobe analysis (EDS) in the scanning electron microscope (SEM). On solidification, $\mathrm{Mn}$ and Fe react with $\mathrm{Al}$ to form the $\beta-\mathrm{Al}_{6}(\mathrm{Fe}, \mathrm{Mn})$, acquiring the morphology shown in the micrographs for all three compositions. Figure 13 shows a SEM micrograph corre- 
sponding to an alloy with a final Mn concentration of $1 \mathrm{wt}$. \%, including a EDS pattern indicating the elements composing the particles.
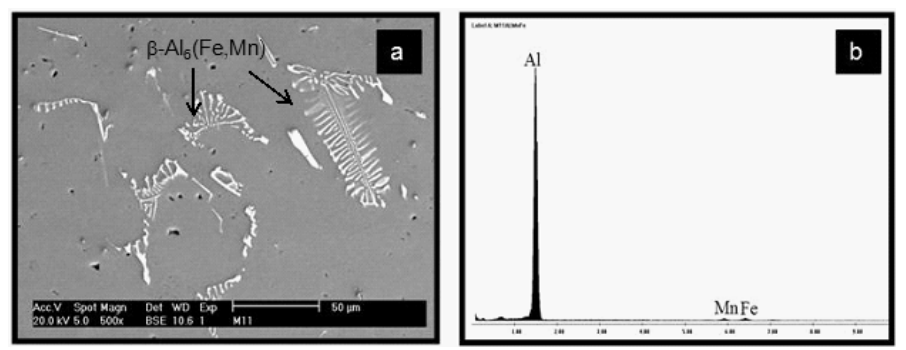

Figure 13. SEM micrograph showing the morphology of: a) $\beta-\mathrm{Al}_{6}(\mathrm{Fe}, \mathrm{Mn})$ : EDS pattern of the $\mathrm{Mn}$ rich particles, in an alloy with a final concentration of $1 \mathrm{wt}$ \% $\mathrm{Mn}$.

In Figure 13 it is observed the presenc particles of the $\beta-\mathrm{Al}_{6}(\mathrm{Fe}, \mathrm{Mn})$ phase, as they can be found in the three different alloys. This phase in the Al-Fe-Mn system is formed around $644^{\circ} \mathrm{C}$ by an eutectic reaction. The particles of $\beta-\mathrm{Al}_{6}(\mathrm{Fe}, \mathrm{Mn})$ remaining in the melt due to incomplete reaction, are dissolved during the homogenization treatment, resulting in the more stable phase $\mathrm{Al}_{15}(\mathrm{Mn}, \mathrm{Fe})_{3} \mathrm{Si}_{2}$ on cooling. For this, silicon plays an important role in precipitation kinetics.

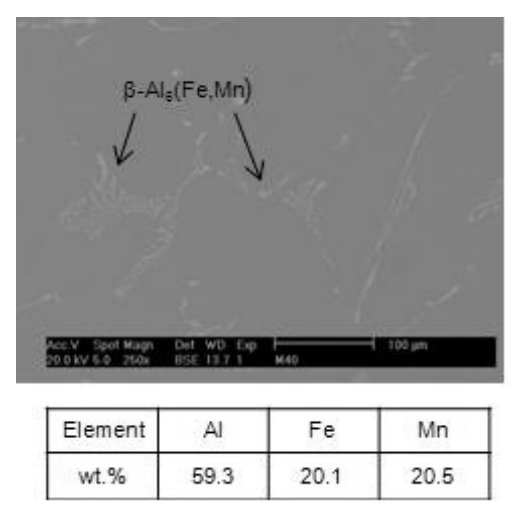

Figure 14. Micrograph obtained by SEM showing the morphology of the particles of the $\beta-\mathrm{Al}_{6}(\mathrm{Fe}, \mathrm{Mn})$ phase, in analloy $\mathrm{Al}-1 \mathrm{wt}$. \% $\mathrm{Mn}$ in the as cast condition.

The microstructure of Al-Mn alloys obtained by aluminothermic reduction process of $\mathrm{Mn}_{2} \mathrm{O}_{3}$ was analyzed by the technique of scanning electron microscopy, in order to observe the morphology of the microconstituents in the solidified alloy, and estimating the semiquantitative composition of the phases present. Figure 14 shows a micrograph of the alloy with $1 \% \mathrm{Mn}$, where it is observed that the second phase particles are $\beta-\mathrm{Al}_{6}(\mathrm{Fe}, \mathrm{Mn})$, homoge- 
neously distributed in the interdendritic spaces. It includes the semi-quantitative chemical analys is results determined by EDS in the SEM.

\subsection{Heattreatment of Al-Mn alloys}

The diversity of the demandson mechanical properties of the semi-finished parts made of aluminium alloys predetermines the choice of heat treatment. In some cases, they require high values of mechanical strengt hand high ductility. In other cases, high ductility is required to ensure good cold deformation to produce specific parts. The correct choice of the types of heat treatment allows obtaining products whose mechanical properties need to be optimized. In the as-cast condition the dendritic structure is not uniform, with precipitation of inter metallic phases in the interdendritic spaces and between the grain boundaries, giving very poor mechanical properties. According to the literature $[15,16]$, the precipitates formed are mainly of the $\beta-\mathrm{Al}_{6}(\mathrm{Fe}, \mathrm{Mn})$ type, to a lesser extentof the $\alpha-\mathrm{Al}(\mathrm{Fe}, \mathrm{Mn}) \mathrm{Si}$ phase, and even some compounds of the Al-FeMnSiCu type.

The homogenization treatment for Al-Mn alloys obtained by the aluminothermic reduction process of $\mathrm{Mn}_{2} \mathrm{O}_{3}$, was carried out in aThermolyne brand Model 4500 furnace at $550^{\circ} \mathrm{C}$ for a holding time of 15 hours.

The homogenization annealing treatment eliminates chemical segregation and large solidification crystals produced by a faulty practice. Moreover, the homogenizationan nealingis used often to achieve a more uniform precipitation of Mn and Fe rich particles, which influence the behavior of the material during recrystallization and hot forming. It is performed at elevated temperatures, near the melting temperature of the alloy, and is mainly applied to alloys with susceptibility to segregation [16].

In Al-Mnalloys, casting structureis characterized by a heterogeneous solution, with primary particles of the $-\mathrm{Al}_{6}(\mathrm{Fe}, \mathrm{Mn})$ phase and minor amounts of $\alpha-\mathrm{Al}(\mathrm{Mn}, \mathrm{Fe}) \mathrm{Si}$ particles. A homogenization treatment before hot rolling is necessary to reduce the concentration of manganese and control the size, density and distribution of particles, as they affect recrystallization, texture and mechanical properties of the alloy informing stages. The addition of alloying elements in the alloys Al-Mn has a strong influence on the behavior of the precipitation. Fe and Sigreatly decreasethe solubility of $\mathrm{Mn}$ in solid solution, accelerating the velocity of precipitation. Fe favors the precipitation of $(\mathrm{Fe}, \mathrm{Mn}$ ) rich particles, while Si favors precipitation of the phase $\alpha-\mathrm{Al}_{12}(\mathrm{Fe}, \mathrm{Mn})_{3} \mathrm{Si}$ in the alloy [2].

The $\alpha$-phase particles have an influence on the formability of the alloy, and has been found that during homogenization treatment, particles of the $\beta-\mathrm{Al}_{6}(\mathrm{Mn}, \mathrm{Fe})$ phase are transformed into $\alpha-\mathrm{Al}_{12}(\mathrm{Fe}, \mathrm{Mn})_{3} \mathrm{Si}$ [15]. According to Luigi [17], the $\alpha-\mathrm{Al}_{12}(\mathrm{Fe}, \mathrm{Mn})_{3} \mathrm{Si}$ particles starts to precipitateon cooling at about $400^{\circ} \mathrm{C}$. The disappearance of the $\beta$ phase precipitates occurs because of silicon diffusion into the matrix, nucleating subsequently the precipitates of the $\alpha-\mathrm{Al}_{12}(\mathrm{Fe}, \mathrm{Mn})_{3} \mathrm{Si}$ phase $[18,19]$. On heating, this transformation has a peak at the temperature of $560{ }^{\circ} \mathrm{C}$, temperature at which the $\beta-\mathrm{Al}_{6}(\mathrm{Fe}, \mathrm{Mn})$ particles starts its dissolution [2].

Figure 15 shows SEM micrographs oft he microstructure of analloy Al-1\% Mn after being subjected to homogenization treatment. In these micrographs it is observed that the bright 
portion corresponds to the phase $\beta-\mathrm{Al}_{6}(\mathrm{Fe}, \mathrm{Mn})$, which by effect of heat treatment are transformedin to $\alpha-\mathrm{Al}_{12}(\mathrm{Fe}, \mathrm{Mn})_{3} \mathrm{Si}$ phase particles. However, complete transformation was not attained, because the treatment temperature was $10^{\circ} \mathrm{C}$ below the the oretical temperature of transformation and, therefore, it requires even more time to reachall of the transformation. Besides the micrographs, it also is included EDS patterns indicating the semi-quantitative chemical composition of these phases, after homogenization treatment.
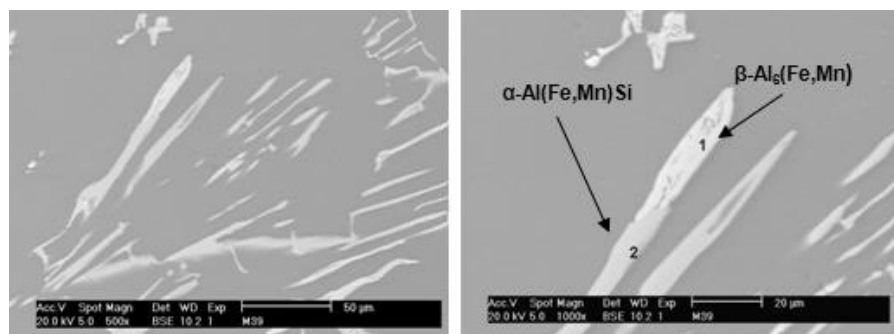

\begin{tabular}{|l|l|l|l|l|}
\hline Phase & Al (wt.\%) & Mn(wt.\%) & Fe (wt.\%) & Si (wt.\%) \\
\hline 1 & 59.3 & 20.1 & 20.5 & - \\
\hline 2 & 47.2 & 23.9 & 24.3 & 4.53 \\
\hline
\end{tabular}

Figure 15. SEM micrograph of an Al-1 wt. \%Mn alloy showing the morphologyof the $\beta-A I_{6}(\mathrm{Fe}, \mathrm{Mn})$ and a$\mathrm{Al}_{12}(\mathrm{Fe}, \mathrm{Mn})_{3}$ Si phases particles after a homogenizing treatmentat $550^{\circ} \mathrm{Cfor} 15$ hours.

The presence of elements such as ironand manganese in the supersaturated solid solution, or affinely dispersed precipitates of small size, difficult subsequent recrystallization processes by inhibiting the movement of atoms and dislocations. Furthermore, the presence of iron or higher contents of silicon, decrease the amount of supersaturated manganese in solid solution, facilitating its separation by forming different compounds [20].

\begin{tabular}{cccc}
\hline Simple & $\boldsymbol{\sigma}_{0}(\mathrm{Mpa})$ & UTS (Mpa) & EI (\%) \\
\hline As-cast & 113 & 181 & 4 \\
\hline Homogenized & 78 & 155 & 11
\end{tabular}

Table 5. Mechanical properties values the alloy Al-1\% Mn obtained by metallothermic reduction of $\mathrm{Mn}_{2} \mathrm{O}_{3}$, in the ascast condition and after homogenization heat treatment.

Additionally, Table 5 shows the values of yield stress $\left(\sigma_{0}\right)$, ultimate tensile stress (UTS), and $\%$ elongation, in order to establish the effects of homogenization treatmenton the mechanical properties of the as-cast alloys. The transformation of the $\beta$ phase to $\alpha$ phase cause dare duction in the values of $\sigma 0$ and UTS, and a significant increase in elongation affinely percentage,indicating that the material will have good mechanical behavior during forming.

From the results shown above, it can be stated that the Al-Mn alloy sobtained by aluminothermic reduction of $\mathrm{Mn}_{2} \mathrm{O}_{3}$ must be submitted to a homogenization treatment before its 
laminationor other deformation process. The phases obtained after homogenization treatmentand the values of the parameters measured indicate that these alloys could have the same behavior in mechanical forming than those obtained using pure elements.

\section{Conclusions}

It is possible to obtain Al-Mn alloys, with concentrations of manganese ranging from 1 to 1.5 wt.\%, using the aluminothermic reduction of $\mathrm{Mn}_{2} \mathrm{O}_{3}$ powders produced from alkaline batteries cathodes. Molten metal is obtained using aluminium cans which act as $\mathrm{Mn}_{2} \mathrm{O}_{3}$ reducer. Aluminothermic reductionis carried out effectively at $800{ }^{\circ} \mathrm{C}$, allowing incorporating up to $1.5 \mathrm{wt}$. \% of $\mathrm{Mn}$ in the solidified alloy. The cost effectiveness of the process is of beneficial interest, as $75 \%$ of savings in the purchase of raw materials for producing alloys from pure materials could be achieved. The Mg contentin aluminium cans play an important role during aluminothermic reduction, as it has direct influence on the wettability of the particles and the chemical reaction rate. The presence of elements such as $\mathrm{Fe}$ and $\mathrm{Si}$, influence the behavior of the alloy on solidification, as well as in the homogenization heat treatment. The as-cast structure consists primarily of particles of the $\beta-\mathrm{Al}_{6}(\mathrm{Fe}, \mathrm{Mn})$ phase, which during the homogenization treatment is transformed into the soft phase $\alpha-\mathrm{Al}_{12}(\mathrm{Fe}, \mathrm{Mn})_{3} \mathrm{Si}$, causing that the alloy can be deformed appropriately. The typ alloys obtained in this work must be submitted to a homogenization heat treatment before its laminationor other process of deformation. The phases obtained after homogenization treatmentand the values of the mechanical properties measured indicate that the Al-Mn alloy obtained by metallothermic reduction of $\mathrm{Mn}_{2} \mathrm{O}_{3}$ could have the same behavior in mechanical forming than those obtained from pure elements.

\section{Acknowledgements}

The authors wish to thank the National Council of Sciences from México (CONACYT), for the funds provided, project CB-2007-01-81251 and to Fundición J.V. S.A. de C.V. from Ramos Arizpe, Coahuila, México, for the technical facilities.

\section{Author details}

A. Flores Valdés *, J. Torres and R. Ochoa Palacios

*Address all correspondence to: alfredo.flores@cinvestav.edu.mx

Centro de Investigación y de Estudios Avanzados del IPN, Unidad Saltillo,, México 


\section{References}

[1] Schlesinger, Mark E. (2007). Aluminium Recycling. Boca Raton, Fl, CRC. Press, Taylor and Francis Group.

[2] Bahadur, Aruna. (1988). Intermetallic phases in Al-Mn alloys. Journal of Materials Science, 23, 48-54.

[3] Li, Y. J., \& Arnberg, L. (2003). Quantitative study on the precipitation behavior of dispersoids in DC-cast AA3003 alloys during heating and homogenization. Acta Materialia, 51-3415.

[4] Carceaga, J. A. (1993). Manejo y reciclaje de residuos de envases. SEDESOL 4 www.sedesol.gob.mx (accessed1993).

[5] Moreno, C. (2008). Las latas, los envases ecológicos por excelencia. Revista Mexicana del Empaque, Embalaje y Plásticos, 313.

[6] Vásquez, R. O. (2011). Últimas noticias del aluminio en México y el mundo. Revista Aluminia, 16, 4-12.

[7] Castro, J., Díaz, M. L., \& Díaz, Castro. (2004). Contaminación por pilas y baterías en México. SEMARNAT. Instituto Nacional de Ecología., www.ine.org.mx, 5-73.

[8] Torres, Cabral. L. G. (2008). Recuperación de zinc y manganeso de baterías alcalinas descargadas utilizando lixiviación. Master'sthesis., CINVESTAV-IPN, Unidad Saltillo, México.

[9] Cortinas, C. (2008). Base para Integrar Planes de Manejo de Pilas y Baterías Eléctricas a Base de Mercurio o de Níquel-Cadmio. Editada por la Red Queretana de Manejo Ambiental de los Residuos, 1-12.

[10] Langlais, Harris R. (1991). Strontium Extraction by Aluminothermic Reduction. Master's thesis, McGill University Montreal, Canada.

[11] Levenspiel, O. (2002). Ingeniería de las Reacciones Químicas, 2da Edición, Barcelona España

[12] Neff, D. V. (1992). Paper presented at The Benefits of Flux Injection Combined With Rotor Dispersion for Producing Clean Aluminium Casting Alloys: proceedings of $3^{\text {rd }}$ International Conference on Molten Aluminium processing, Orlando-Florida, USA.

[13] Davis, J. R. (1990). Metals Handbook. 9th Edition. Nonferrous Molten Metal Process. ASM U.S.A. , 15

[14] King, F. (1987). Aluminium and its Alloys. Chichester, Ellis Horwood Limided.

[15] Salvador, M. D., Amigo, V., Reig, L., Bloem, C., Carsí, M., \& Caruna, G. (2007). Evolución microestructural y mecánica de una aleación de aluminio de la serie 3xxx obtenida por el proceso Hazelett. Revista de metalurgia, 43(6), 424-433. 
[16] Qiang, Du., Poole, Warren J., Wells, Mary. A., \& Parson, Nick. (2011). Microstructural modeling of the homogenization heat treatment for AA3XXX alloys. JOM, 63(7), 35-39.

[17] Luiggi, A., \& Ney, J. (2010). A Preliminary Study of the Phase Transformations in Rolled Al-Fe-Si Alloy. Metallurgical and Materials Trasactions A, 41(13), 3271-3275.

[18] Kamat, R. G., \& Saimoto, S. (1994). Microestructure and Texture evolution in continuously cooled AA 3004 hot rolled sheet. Materials Science Technology., 10(3), 215-221.

[19] Langlais, Alexander D.T.L. (2011). Solid-state intermetallic phase tranformations in 3XXX aluminium alloys. Acta Materialia, 50, 2571 -2583.

[20] Li, Y. J., Mueggerud, A. M. F., Olsen, A., \& Furu, T. (2012). Precipitation of partially coherent $\alpha$-Al(Fe,Mn)Si dispersoids and their strengthening affect in AA 3003 alloy. Acta Materialia, 60, 1004-1014. 